\title{
Karakteristik Pasien Adenomiosis dengan Gambaran Ultrasonografi di Rumah Sakit Dr. Hasan Sadikin Bandung Periode 2015-2016
}

\author{
Meice Fitrina, Hartanto Bayuaji, Tita Husnitawati Madjid, Edwin Armawan \\ Departemen Obstetri dan Ginekologi Fakultas Kedokteran Universitas Padjadjaran \\ Rumah Sakit Dr. Hasan Sadikin Bandung \\ Korespondensi: Meice Fitrina, Email: meicefitrina@gmail.com
}

\begin{abstract}
Abstrak
Tujuan: Karakteristik pasien dan hasil pemeriksaan ultrasonografi penting untuk menegakkan diagnosis adenomiosis, dapat diketahui terkait dari usia, gejala dan paritas serta pemeriksaan patologi anatomi.

Metode: Deskriptif retrospektif menganalisis gejala klinis dan ultrasonografi adenomiosis. Data demografi (usia dan paritas), gejala klinis, hasil pemeriksaan ultrasonografi, dan hasil pemeriksaan patologi anatomi.

Hasil: Dari 116 kasus, rata-rata usia adalah 39 tahun, paritas 1 - 4 (51,7\%), infertilitas sekunder (35,3\%), dengan gejala klinis yang terbanyak adalah massa pada abdomen $(45,7 \%)$. Hasil pemeriksaan ultrasonografi yang terutama adalah miometrium heterogen $(63,8 \%)$, kista miometrium $(59,5 \%)$, dan subendometrial linear striae $(56,0 \%)$. Hasil pemeriksaan USG transvaginal yang paling banyak ditemukan gambaran miometrium heterogen $(63,8 \%)$ dan kista miometrium $(59,5 \%)$.

Kesimpulan: Adenomiosis umum terjadi pada usia reproduktif dan multiparitas dengan gejala utama massa pada abdomen dan hasil ultrasonografi yang terutama ditemukan adalah miometrium heterogen.
\end{abstract}

Kata kunci: adenomiosis, ultrasonografi, ultrasonografi transvaginal

\section{Characteristics Overview of Adenomyosis Patients with Ultrasonographic at Dr. Hasan Sadikin Bandung General Hospital during 2015-2016}

\begin{abstract}
Objective: Characteristic patient and ultrasonography findings are important to make a diagnosis of adenomyosis. To describe common and uncommon characteristics patients which is include age, symptoms, and parity with ultrasonographic findings and histopatolgic examination of adenomyosis.

Methods: This study was a descriptive restrospective study in adenomyosis cases. Patients with clinical symptoms and confirmed with ultrasonographic was an adenomyosis were analyzed.

Results: Out of 116 cases, mean age was $>35$ years old (70,7\%), parity was $1-4(51,7 \%)$, related to secondary infertility (35,3\%), with most common symptom is abdominal mass (45,7\%). Most common findings of ultrasonographic were heterogenous myometrium (63,8\%), myometrium cyst (59,5\%), and subendometrial linear striae / shadowing (56,5\%). Sign transvaginal ultrasound were the heterogeneous myometrium (63.8\%) and myometrial cyst (59.5\%).

Conclusion: Adenomyosis usually happen in reproductive age, multiparity with main symptoms is abdominal mass and the most common sonographic findings is heterogenous myometrium.
\end{abstract}

Keywords: adenomyosis, ultrasonographic, transvaginal ultrasonography. 


\section{Pendahuluan}

Adenomiosis adalah invasijinak endometrium ke miometrium, dengan adanya kelenjar dan stroma endometrium dari lapisan basal endometrium terdapat di lapisan myometrium yang mengalami hipertrofi dan hiperplasia menyebabkan uterus membesar sehingga disebut sebagai "uterus globular". Prevalensi terjadi sekitar 20 - 30\% pada populasi wanita usia 40 - 49 tahun, juga berkaitan dengan endometriosis dan multiparitas. ${ }^{1,2}$

Patofisiologi adenomiosis masih belum jelas, tetapi teori baru mengatakan bahwa terdapat perbedaan pada zona perbatasan antara endometrium dan miometrium. Adenomiosis juga berkaitan dengan terjadinya infertilitas dan endometriosis. Diperlukan diagnosis yang tepat dalam menegakkan diagnosis adenomiosis. Namun, adenomiosis sering sekali sulit ditegakkan karena menyerupai penyakit lainnya yaitu leiomioma dengan gejala klinis dan pemeriksaan ultrasonografi yang menyerupai. ${ }^{3,4}$

Keluhan adenomiosis yang klasik adalah perdarahan abnormal, nyeri panggul, nyeri saat menstruasi, nyeri saat berhubungan badan, terkadang bersifat asimptomatik. Diagnosis pasti adenomiosis dapat ditegakkan dengan pemeriksaan histopatologis. Pada pemeriksaan mikroskopik ditemukan kelenjar dan jaringan endometrium yang mengelilingi miometrium. Juga dapat dilakukan dengan pemeriksaan pre-operasi dengan ultrasonografi (USG) transvaginal. Pemeriksaan penunjang dengan USG transvaginal dapat melihat pembesaran uterus yang globuler, kista an-ekoik, penebalan dinding miometrium asimetris terutama pada dinding posterior, miometrium yang heterogen, endometrial-myometrial junction tidak jelas, dan subendometrial linear striae. USG transvaginal memiliki sensitifitas $82.5 \%$ dan spesifitas untuk mendiagnosis adenomiosis $84.6 \%$. Pemilihan penggunaan USG transvaginal dikarenakan lebih murah. 5, 6, 7,8 Di Indonesia belum terdapat data mengenai diagnosis adenomiosis dengan temuan dari hasil pemeriksaan USG transvaginal, sehingga peneliti tertarik melakukan penelitian ini dengan tujuan mempermudah para klinisi dalam menegakkan diagnosis adenomiosis.

\section{Metode}

Penelitian ini merupakan penelitian retrospektif dengan pendekatan deskriptif. Data yang digunakan merupakan data sekunder yang diambil dari pemeriksaan ultrasonografi catatan medis dan data dari hasil operasi serta pemeriksaan patologi anatomi penderita adenomiosis pada tahun 2015-2016 di rumah sakit umum pendidikan RSUP Dr. Hasan Sadikin Bandung yang disajikan dalam bentuk tabel. Penelitian dilaksanakan di Poliklinik Ginekologi RSUP Dr. Hasan Sadikin Bandung. Penelitian dilakukan periode Januari - Juni 2017 dengan subjek penelitian adalah semua penderita adenomiosis yang dilakukan pemeriksaan USG transvaginal dan operasi. Pada penelitian ini, kriteria hasil pemeriksaan ultrasonografi yang diambil adalah: ${ }^{2,3}$ uterus globuler: uterus yang membesar hingga diameter berukuran $12 \mathrm{~cm}$, tanpa gambaran mioma uteri, myometrial cyst: area kistik bersifat an-ekoik dengan berbagai ukuran bervariasi antara 1-7 $\mathrm{mm}$ dan terdapat di lapisan miometrium dan subendometrium, asymetricalmyometrial thickening:jarak antar endometrium ke dinding posterior lebih tebal daripada dinding anterior, Subendometrial echogenic linear striations (shadowing): invasi dari kelenjar endometrium ke jaringan subendometrium yang menimbulkan reaksi hiperplasia berupa garis linear ekogenik, Batas Endometrial Miometrial Junction (EMJ) irregular : invasi kelenjar endometrium ke miometrium menyebabkan batas endometrium-miometrium menjadi tidak jelas dan Heteregeneous myometrium: 
homogenitas lapisan miometrium berkurang.

\section{Hasil}

Penelitian telah dilakukan pada 116 penderita adenomiosis. Didapatkan bahwa kasus adenomiosis banyak terdapat pada usia reproduktif yaitu usia $>35$ tahun sebanyak 82 penderita $(70,7 \%)$ dengan usia rerata 39 tahun, paritas 1 - 4 sebanyak 60 penderita $(51,7 \%)$ dan seringkali terkait dengan infertilitas sekunder. Gejala adenomiosis yang paling banyak yaitu benjolan di perut dengan gejala penyerta antara lain adalah dismenore, dan perdarahan. Diagnosis awal adenomiosis pada 66 penderita $(58,5 \%)$ dengan temuan hasil USG transvaginal terbanyak adalah ditemukannya gambaran miometrium yang heterogen sebanyak 74 penderita $(63,8 \%)$, ter

Tabel 1 Karakteristik Subjek Penelitian

\begin{tabular}{lcc}
\hline \multicolumn{1}{c}{ Variabel } & $\mathbf{n = 1 1 6}$ & $\mathbf{\%}$ \\
\hline $\begin{array}{l}\text { Umur } \\
<20 \text { tahun }\end{array}$ & 1 & 0,9 \\
& & \\
$20-35$ tahun & 33 & 28,4 \\
$>35$ tahun & 82 & 70,7 \\
Paritas & & \\
0 & 54 & 46,6 \\
$1-4$ & 60 & 51,7 \\
$>4$ & 2 & 1,7 \\
Status & & \\
Pernikahan & & \\
Menikah & 108 & 93,1 \\
Tidak & 8 & 6,9 \\
\hline
\end{tabular}

\section{Tabel 2 Gambaran Keluhan Penderita} Adenomiosis

\begin{tabular}{lcc}
\hline \multicolumn{1}{c}{ Variabel } & n =116 & \% \\
\hline Dismenorea & 49 & 42,2 \\
Perdarahan & 14 & 12,1 \\
Benjolan di & 53 & 45,7 \\
Perut & &
\end{tabular}

dapat kista myometrium sebanyak 69 penderita $(59,5 \%)$ dan gambaran subendometrial linear striae (shadowing) sebanyak 65 penderita $(56 \%)$.

\section{Tabel 3 Gambaran Temuan Ultrasonografi Penderita Adenomiosis}

\begin{tabular}{lcc}
\hline \multicolumn{1}{c}{ Variabel } & $\mathbf{n = 1 1 6}$ & $\mathbf{\%}$ \\
\hline Uterus Globuler & & \\
Ya & 50 & 43,1 \\
Tidak & 66 & 56,9 \\
Asimetris Miometrium & & \\
Ya & 34 & 29,3 \\
Tidak & 82 & 70,7 \\
Miometrium & & \\
Heterogen & & \\
Ya & 74 & 63,8 \\
Tidak & 42 & 36,2 \\
Kista Miometrium & & \\
Ya & 69 & 59,5 \\
Tidak & 47 & 40,5 \\
Endometrial & & \\
Miometrial Junction & & \\
Tidak Jelas & & \\
Ya & 43 & 37,1 \\
Tidak & & \\
Subendometrial & 73 & 56,9 \\
Linear Striae & & \\
Ya & & \\
Tidak & 65 & \\
\hline
\end{tabular}

\section{Pembahasan}

Dalam penelitian ini ditemukan bahwa karakteristik penderita adenomiosis banyak pada usia dewasa reproduktif (premenopause) $>35$ tahun dan multiparitas dengan jumlah paritas 14 yaitu 60 penderita $(51,7 \%)$. Triad gejala klasik adenomiosis yaitu pembesaran uterus, dismenorea dan menorrhagia. Gejala klinis ini tidak spesifik karena dapat terjadi pada mioma uteri, sehingga diagnosis adenomiosis sering terjadi kesalahan diagnosis dengan mioma uteri. Spesifitas diagnosis pre-operatif adenomiosis berdasarkan klinis sangat rendah $\pm 2-26 \%$. 
Dahulu, diagnosis adenomiosis berdasarkan penilaian dari jaringan histopatologis pada saat dilakukan operasi histerektomi oleh karena itu sering terlambat terdiagnosa. Akan tetapi, saat ini diagnosis adenomiosis dapat ditegakkan dengan pemeriksaan USG transvaginal dengan sensitivitas $65-81 \%$ dan spesifitas $65-100 \%$ serta biaya lebih murah, terjangkau dan banyak tersedia.

Diagnosis paling sensitif adalah ditemukan adanya miometrium heterogen (spesifitas 80\%, akurasi 75\%). Menurut Shwayder dkk, yang paling sering ditemukan pada pemeriksaan USG transvaginal adalah miometrium heterogen diikuti oleh uterus berukuran globuler serta kista miometrium dan asimetris pada miometrium. Sementara yang jarang ditemukan pada pemeriksaan USG transvaginal adalah subendometrial linear striae (shadowing). Sedangkan menurut Vinci dkk yang paling sering ditemukan adalah asimetris pada miometrium dan subendometrial linear striae (shadowing) diikuti oleh kista pada miometrium sedangkan yang paling jarang ditemukan adalah gambaran endometrial miometrial junction tidak jelas.

Pada penelitian yang dilakukan, dari hasil pemeriksaan USG transvaginal yang paling banyak ditemukan adalah gambaran miometrium heterogen pada 74 penderita $(63,8 \%)$ dan kista miometrium pada 69 penderita (59,5\%). Gambaran USG transvaginal yang jarang ditemukan adalah asimetris miometrium pada 34 penderita $(29,3 \%)$ dan gambaran endometrial miometrial junction tidak jelas pada 43 penderita $(37,1 \%)$. Hal ini dipengaruhi oleh keterampilan operator dalam menggunakan USG transvaginal, kemampuan operator dalam menemukan semua gambaran adenomiosis secara USG serta alat USG yang digunakan. Simpulan pada penelitian ini, kasus adenomiosis banyak terdapat pada usia reproduktif dengan rerata usia 39 tahun dari 116 penderita dengan pemeriksaan
USG transvaginal didapatkan gambaran yang terbanyak adalah miometrium yang heterogen $(63,8 \%)$ diikuti oleh gambaran kista pada miometrium $(59,5 \%)$ serta gambaran subendometrial linear striae/ shadowing $(56,0 \%)$.

\section{Saran}

Diperlukan peningkatan keterampilan kompetensi USG transvaginal untuk pemeriksa sehingga dapat menemukan semua kriteria gambaran adenomiosis sehingga mempermudah dalam mendiagnosa suatu adenomiosis.

\section{Daftar Pustaka}

1. Exacoustos C, Manganaro L, Zupi E. Imaging for the evaluation of endometriosis and adenomyosis. index medical

2. Shwayder J, Sakhel K. Imaging for uterine myomas and adenomyosis. Journal of minimal invasive gynecol. 2014;21(3):362-76.

3. Naftalin J, Hoo W, Pateman K, Mavrelos D, Holland T, Jurkovic D. How common is adenomyosis? A prospective study of prevalence using transvaginal ultrasound in a gynaecology clinic. Hum Reprod. 2012;27(12):3432-9.

4. Dueholm M, Lundorf E. Transvaginal ultrasound or MRI for diagnosis of adenomyosis. Curr Opinions in Obstet and Gynecol. 2007;19(6):505-12.

5. Vinci V, Saldari M, Sergi ME, Bernardo S, Rizzo G, Porpora MG, et al. MRI, US or real time virtual sonography in the evaluation of adenomyosis? Radiol Med. 2017;122(5): 361-8.

6. Lin $\mathrm{P}$, Sun Y-L, Wang C-B, Lee C-Y, Wun T-H, Lin Y-H, et al. Transvaginal sonographic criteria for the diagnosis of adenomyosis based on histopathologic correlation. Taiwanese journal of 
obstetrics and gynecology. 2010;49(1): 40-4.

7. Bayuaji $\mathrm{H}$, dkk. Ultrasonografi Transvaginal. Departemen/SMF Obstetri dan Ginekologi Fakultas Kedokteran Universitas Padjadjaran RSUP dr. Hasan Sadikin. Bandung. 2016
8. Berek J.S. etc. 2012. Berek \& Novak's Gynecology. Philadelphia. $15^{\text {th }}$ Ed. Section IV: General Gynecology; 484-5. 